\title{
Animal Models of CNS Viral Disease: Examples from Borna Disease Virus Models
}

\author{
Marylou V. Solbrig \\ Department of Internal Medicine (Neurology) and Medical Microbiology, University of Manitoba, Winnipeg, MB, Canada R3A 1 R9 \\ Correspondence should be addressed to Marylou V. Solbrig, msolbrig@uci.edu \\ Received 1 October 2009; Accepted 8 December 2009 \\ Academic Editor: Guey Chuen Perng \\ Copyright () 2010 Marylou V. Solbrig. This is an open access article distributed under the Creative Commons Attribution License, \\ which permits unrestricted use, distribution, and reproduction in any medium, provided the original work is properly cited. \\ Borna disease (BD), caused by the neurotropic RNA virus, Borna Disease virus, is an affliction ranging from asymptomatic to \\ fatal meningoencephalitis across naturally and experimentally infected warmblooded (mammalian and bird) species. More than \\ 100 years after the first clinical descriptions of Borna disease in horses and studies beginning in the 1980's linking Borna disease \\ virus to human neuropsychiatric diseases, experimentally infected rodents have been used as models for examining behavioral, \\ neuropharmacological, and neurochemical responses to viral challenge at different stages of life. These studies have contributed to \\ understanding the role of CNS viral injury in vulnerability to behavioral, developmental, epileptic, and neurodegenerative diseases \\ and aided evaluation of the proposed and still controversial links to human disease.
}

\section{Introduction}

Why do we need animal models for neurotropic viral studies? Some day, human functional neuroimaging may provide consistent reliable experimentation in our species, or genetic biomarkers may have predictive validity for disease course or vulnerability. However, until detailed neuroanatomical, molecular and cellular changes needed to understand CNS viral pathogenesis become accessible by these methods, animal models will be needed to evaluate agent-specific and general principles of neurovirology.

In 1985, when Borna disease virus (BDV) was proposed as an etiologic agent of bipolar affective disorder based on detection of BDV antibodies in serum of 1.6\% (16/979) of psychiatric patients [1], work on BDV infection of small laboratory animals was well underway. By 1988, when the virus had been implicated in affective disorders and schizophrenia [2], experimental work was expanding and becoming increasingly reliant on in vivo animal studies. Small laboratory animals could be readily infected and demonstrate signs of disease in a short, predictable time frame. Rats and mice offered specific advantages, because rodent nervous systems had been extensively mapped. In time, the use of select animal models would elucidate many neurobiological substrates of viral injury and disrupted behavior, and aid in testing the hypothesis that BDV may be a cause of human neuropsychiatric diseases. The experimental history of use of behaving animals as subjects in Borna disease virus research is the subject of this review.

\section{History of Borna Disease Virus}

Borna disease (BD) was a sporadic, epidemic encephalitis of horses and sheep in 18th and 19th century Central Europe, described as hitzige Kopfkrankheit "heated head disease" of cavalry horses in 1885 in the town of Borna in Saxony, Germany [3-5]. In horses, a variety of syndromes were recognized, including excitability and hyperactivity, movement and posture disorders $[4,6,7]$. Although typically fatal, there was sufficient variability in expression and progression of $\mathrm{BD}$ to imply that host, age, virus strain, and mode of infection may influence disease. Whether clinical features vary with host attributes or immune status would be followed up by veterinary pathologists and virologists.

Work in experimental BDV infection, begun in rats in the 1960's [8] accelerated in the 1970's and 1980's with more rats, as well as mice, rabbits, tree shrews, and rhesus monkeys. Borna disease had distinct characteristics across species [6]. For example, rats showed hyperactive movements, behavior disorders, and poor maze learning [9-12] while most strains 
of mice were asymptomatic [13]. Rhesus monkeys showed hyperactivity, aggression, disinhibited behaviors then apathy [14], and tree shrews, a lower primate, displayed abnormal sexual and social behaviors [15]. For study of BDV, small laboratory animals were becoming an experimentally accessible, less expensive, and reproducible alternative to post mortem study of large domestic farm animals.

Early experimental animal work used Strain V, Giessen strain $\mathrm{He} / 80$ (Hessen/80) or field strains: wild-type virus from brain suspensions from horses that had recently died. Strain V originated from a naturally infected horse in 1929. Strain V was first prepared as wild-type virus in horse brain homogenate, then developed as a rabbit-adapted $\mathrm{BD}$ virus [3] and later rat- or mouse-adapted by serial brain passage in newborn rats or mice [11]. He/80, another horse-derived BDV isolate, was prepared first in rabbits by intracerebral inoculation and cultures of fetal rabbit brain, and then rator mouse-adapted by serial brain passage in newborns of the intended experimental species [10].

Not long after reports of an expanding natural host range [5] and demonstration of a broad experimental host range for BDV, came reports of the virus' association with human neuropsychiatric diseases. From the 1985 proposal that Borna disease virus was an etiologic agent of manicdepressive disorders [1], a large number of reports linking Borna disease virus to human affective disorders, schizophrenia, CNS inflammatory and degenerative diseases followed. The associations and controversies regarding human diseases are discussed in several comprehensive reviews $[16,17]$. The early associations with human disease drove the development and further expansion of $\mathrm{BD}$ animal model systems and testing paradigms. Animal models could be used to address very specific questions, whether Borna disease virus is a cause or cofactor in human neuropsychiatric disease, for example, based on development of serologic, detection and transmission criteria, or recognition of biomarkers of disease.

In addition, the animal models could be used to advance more abstract lines of investigation: whether neurotropic viruses would elucidate aspects of nervous system function and plasticity. Because BDV was associated with psychiatric diseases of man in the late 1980's, diseases with no underlying histopathology by standard microscopy techniques of the time, investigators began to consider whether infection by a non-lytic, slow-growing, neurotropic virus itself could render CNS pharmacologic and neurochemical changes. The background and experimental paradigms for ascertaining the validity of virus-induced neurotransmitter effects were already in place, due to widening knowledge of the functional anatomy, neuropharmacology and neurochemistry of prefrontal, motor, reward, and limbic circuits rendered by animal models developed during the 1980's and 1990's [18]. Animal models for addiction and psychiatry were some of the most robust in neurobiology. The recording of movement, behavior or cognitive disorders in experimentally infected rodents $[9-12,19,20]$ and primates $[14,15]$, led to the study of these syndromes in the context of specific circuit, neurotransmitter or pharmacologic paradigms. In other words, a neural (neurotransmitter) systems approach to solving a problem in viral pathogenesis, such as how BDV causes movement and behavior disorders in affected species, developed. The approach would rely heavily on behavioral testing.

\section{Adolescent-Infected Rats}

In experimentally-infected adolescent rats, BDV caused a multiphasic syndrome characterized by hyperactivity, dyskinesias, stereotypies, excitability, stimulus sensitivity, selfmutilation, followed by dystonia, ataxia, paresis, seizures and premature senescence $[9,19]$. Interestingly, the early stage of disease resembled psychostimulant sensitization or overdose in rats. Looking like a syndrome of apparent dopamine (DA) excess or sensitivity, Borna disease of rats could be probed with specific pharmacologic agents to establish the neuropharmacological basis for the behaviors. Behavioral supersensitivity to the dopaminergic psychostimulants damphetamine [19] and cocaine [21] was shown using photocell cages for automated activity recordings and behavior rating scales developed for the study of amphetamine doseresponse curves in rats.

Demonstration of psychostimulant sensitivity was followed by study of pre- and postsynaptic effects of infection in dopaminergic extrapyramidal motor and reward circuits. In the nigrostriatal system, partial DA deafferentation and compensatory hyperactivity in surviving striatal nerve terminals [19] along with tyrosine hydroxylase (TH) hyperphosphorylation and TH metabolic hyperactivity in nigrostriatal projections [22] were bases for locomotor hyperacitivity and stimulant sensitivity. Reduced dopamine D2 and D3 receptors but preserved D1 receptor numbers in striatum (caudate putamen and nucleus accumbens) $[19,23]$ underlay the $\mathrm{BD}$ rat's motor dyskinesias and later stage dystonia. Reduced D2 striatal receptors and the reduced indirect striatal pathway throughput that results, is the primary pathology also of Huntington's disease, the choreic syndrome of man. Hyperactivity and fearless, disinhibited behaviors were associated with metabolic changes in the prefrontal DA circuits [24], while cognitive decline was linked to forebrain cholinergic loss $[25,26]$, a pathology of Alzheimer's disease.

The neuropharmacologic and neurochemical changes supported the possibility of a link between BDV and human neuropsychiatric syndromes with dopaminergic substrates, such as schizophrenia, extrapyramidal (movement) disorders, addictions, or cholinergic substrates, such as dementia. Further evidence of neuropharmacologic consequences of infection was provided by successfully treating $\mathrm{BD}$ rat abnormal behaviors with the atypical neuroleptic clozapine, or the D1 receptor antagonist SCH23390 [19], which reduces self-mutilation behaviors in Lesch-Nyhan patients.

Since the dopamine system is not mature in adolescent rats, the changes in transmitter levels, synthetic and catabolic enzymes, and receptor numbers described could reflect direct, indirect viral effects, and some of the plastic consequences of early life viral insult. However, the most extensive evaluation of neurodevelopmental consequences of early life viral exposure has been with neonatally infected rats. Lewis rats intracerebrally infected at birth were the first virus-induced Autism-Spectrum Disorders models. 


\section{Neonatal-Infected Rats}

Borna disease of neonatally infected rats is a global neurodevelopmental disorder with psychomotor abnormalities, developmental delay, and learning difficulties measured by behavioral tests of reflexes, stance, balance, posture, gait, socialization, learning and play [27-29]. In neonatallyinfected animals, the development of neuropathology roughly parallels the timecourse of microglial proliferation and expression of MHC (major histocompatibility complex) class I and class II, ICAM (intercellular adhesion molecule), CD4 and CD8 molecules [30]. Inflammatory, survival, and proapoptotic signals drive remodelling of the brain from early life. Highly plastic systems, such as the monoamines (dopamine, norepinephrine and serotinin) show changes that include reduced serotonin transmission [31-33], an important link to both autism and depression. The anatomic systems that register early life reflexes and programs, such as cerebellum and hippocampus, are permanently changed [28, 32, 34-39]. In fact, in rats, early life infection by BDV without an associated cellular inflammatory response in brain, produces many of the same neuroanatomical, neurochemial, neuroimmune and behavior changes recognized in children with Autism Spectrum Disorders. Significant parallel changes or sequelae include a dysplastic cerebellum, dissolution of the hippocampal dentate gyrus, early life deficits in hippocampal serotonin, and abnormalities in domains of social (play) behavior, emotion (chronic anxiety), and cognition (poor performance on spatial learning and memory) [40].

Whether neonatally infected BD rats specifically model viral effects in utero or effects on infant or child development depends on the experimental question and which regions, anatomic features, or behaviors are studied. For example, the birth of the majority of granule cells of dentate gyrus of hippocampus that takes place during first postnatal month in rats, occurs prenatally in man [41]. In this respect, the gross structure of the hippocampus of a newborn rat approximately matches a third trimester human. Therefore, disordered macroscopic development of hippocampus, as complex function of microglia activation [30, 42], neurotrophin and cytokine signaling [28, 43-45], metabolic and oxidative stress $([36,37,39]$, also described in adult infected animals, [46, 47]) has direct relevance to in utero virus exposure in man.

Alternatively, other outcome measures have relevance for post-natal or early life consequences of CNS viral exposure or injury. For example, synapse density in the molecular layer of hippocampus reaches adult levels at 21 postnatal days in rat and 7-10 postnatal months in man [41]. Structural causes of disability acquired in infancy would be related to reductions in synaptic growth-associated protein GAP-43, synaptophysin [48], connexin36 [49], and binding of BDV p24 phosphoprotein to neurite growth promoter, amphoterin/HMG-1 [50] found in neonatally infected rats. On the other hand, hippocampal-dependent learning and memory is established 15-16 postnatal days in rat, 4-5 postnatal years in man $[41,51]$, such that tests of learning can model consequences of viral exposure across a broad span of childhood. Acquisition of spatial and aversive learning, shown to be poor as neonatally infected $\mathrm{BD}$ rats mature [12], was associated with increased NPY (neuropeptide Y) expression in hippocampus [52]. Since NPY overexpressed in hippocampus of transgenic rats is associated with spatial learning deficits [53], the results from the BD rats are consistent with NPY upregulation being a viral induced neurochemical cause of compromised learning. The results reflect changes in a cognitive neurotransmitter system that is highly plastic throughout life, contributing to our understanding of neuropeptides in childhood learning.

\section{Mice}

Mice have bridged the gaps between pathogen to behavior and genes to behavior in several important ways. Transgenic technology has enabled studies of the role of individual Borna proteins in disease and molecular genetic mouse models have established mechanisms of host susceptibility and disease outcome.

A transgenic mouse model based on astroglial expression of the BDV phosphoprotein, had reduced BDNF (brain derived neurotrophic factor) levels, serotonin receptor transcripts and synaptic density, and behavioral abnormalities similar to those of neonatal rat infection [54]. Transgenic mice expressing the BDV nucleoprotein in neurons or astrocytes have decreased susceptibility to homotypic infection and disease [55].

Immune determinants of Borna disease have been investigated using genetic and molecular genetic mouse models [56]. Mice, similar to rats, could be infected with BDV by intracerebral inoculation once natural $\mathrm{BDV}$ isolates were mouse-adapted by serial passages in rat brain [57]. Most laboratory strains of mice develop persistent infection but remain well [57]. MRL strain mice are an exception, developing meningoencephalitic Borna disease and hyperactive, disinhibited behaviors after adolescent infection [13]. As in rats, severe clinical disease of mice is mediated by $\mathrm{MHC}$ class I restricted cytotoxic T cells [58]. Wild type MRL mice infected as neonates develop symptomatic disease mediated by antiviral CD8+ T cells, in contrast to $\beta 2$ microglobulinknock out MRL mice lacking CD8 $+\mathrm{T}$ cells that remain well [58]. In another $\beta 2$ microglobulin-deficient strain, C57BL/10J, also lacking CD8+ T cells, BDV-mice develop persistent non-cytolytic infection with most neurons of hippocampus containing viral antigen. Only mice having high transcript levels of interferon-gamma (IFN- $\gamma)$ inducible protein IP-10, a CXC chemokine and chemoattractant for CXCR3+ T cells, showed poor performance on the water maze test of spatial memory and hippocampal function [59, $60]$. CNS infection without hippocampal neuronal loss or maldevelopment distinguished neonatal mice from neonatal rat infections, and established a role of IFN- $\gamma$ on behavior and learning when the hippocampus is apparently intact or without structural damage by infection.

Further studies have found differences across species in susceptibility of BDV to the antiviral action of IFN- $\gamma$. Rat IFN- $\gamma$ is less efficient at blocking or reducing infection in 
rat cell lines than is human IFN- $\gamma$ at limiting or clearing virus from cells of human and nonhuman primate lineage [61].

\section{Rats or Mice?}

A switch to mice has never been complete. In many practical respects, rats are superior to mice, such as subjects of complex behavior or electroencephalographic studies. Biological strategies for gene silencing, such as small interfering RNA technology, may return some laboratories to the use of rats.

Meanwhile, BD rats can still make contributions to understanding gene $\times$ environment vulnerability questions if the human genetics of a disease are known. For example, epilepsy vulnerability has been associated with a dynorphin promoter region polymorphism, or low dynorphin expression genotype, in man [62]. In animals, the dynorphin system in the hippocampus is known to regulate excitability [63]. The hypothesis that reduced dynorphin expression in the dentate gyrus of hippocampus due to periadolescent virus exposure leads to epileptic responses was successfully tested with adolescent-infected BD rats. Epileptic effects were associated with an absence of dynorphin from the dentate gyrus granule cell layer, thus reproducing a neurochemical marker of epilepsy, namely low dynorphin tone [64].

\section{Conclusion}

Well-chosen animal models can be powerful tools for revealing how CNS viral infection results in disrupted behavior. The methods of behavioral research (use of photocell cages, video tracking, operant measures, EEG and telemetry, developmental ethnograms in home cages and test situations) were not the usual procedures and experimental vocabulary of virus researchers. However, research in BDV has helped to change that. Work on BDV in many labs over 2-3 decades has illustrated the choices of subject and test procedures that yielded important insights into pathogenesis. Work on adolescent-infected rats has shown how infection can cause long-term changes in emotional behavior and cognitive capacity. Work on neonatal rats has shown how infections during brain development can cause long-term changes in behavior and cognitive capacity. Studies on mice have shown infections during brain development can cause longterm changes in these parameters in genetically vulnerable individuals. All together, the studies have shown BDV causes pharmacologic and lesion effects in experimentally infected species with disease outcome related to genetic background and/or developmental maturity of nervous system at the time of viral exposure. The same drugs that treat psychiatric diseases of man treat or suppress the abnormal behaviors of infected rodents. A next step may be to make greater use of models based on genetic variants relevant for neuropsychiatric disorders to study outcomes of infection. It is anticipated that work on BD in animal models will continue to elucidate aspects of nervous system function and disease.

\section{Acknowledgments}

The author's lab has been supported by NIH DA 00376, NS 042307, the Charles and Diane Karp Foundation, and the University of Manitoba Medical Group.

\section{References}

[1] R. Rott, S. Herzog, B. Fleischer, et al., "Detection of serum antibodies to Borna disease virus in patients with psychiatric disorders," Science, vol. 228, no. 4700, pp. 755-756, 1985.

[2] L. Bode, S. Riegel, H. Ludwig, J. D. Amsterdam, W. Lange, and $\mathrm{H}$. Koprowski, "Borna disease virus-specific antibodies in patients with HIV infection and with mental disorders," The Lancet, vol. 2, no. 8612, p. 689, 1988.

[3] W. Zwick, "Borna'sche krankheit und encephalomyelitis der tiere," in Handbuch der Viruskrankheiten, F. Gildemeister, E. Haagen, and O. Waldmann, Eds., vol. 2, pp. 252-354, Fischer, Jena, Germany, 1939.

[4] H. Ludwig and P. Thein, "Demonstration of specific antibodies in the central nervous system of horses naturally infected with Borna disease virus," Medical Microbiology and Immunology, vol. 163, no. 4, pp. 215-226, 1977.

[5] R. O. Waelchli, F. Ehrensperger, A. Metzler, and C. Winder, "Borna disease in a sheep," The Veterinary Record, vol. 117, no. 19, pp. 499-500, 1985.

[6] H. Ludwig, L. Bode, and G. Gosztonyi, "Borna disease: a persistent virus infection of the central nervous system," Progress in Medical Virology, vol. 35, pp. 107-151, 1988.

[7] M. V. Solbrig, J. H. Fallon, and W. I. Lipkin, "Behavioral disturbances and pharmacology of Borna disease," Current Topics in Microbiology and Immunology, vol. 190, pp. 93-101, 1995.

[8] E. Nitzschke, "Investigation about the experimental Bornavirus-infection in the rat," Journal of Veterinary Medicine B, vol. 10, pp. 470-527, 1963 (German).

[9] O. Narayan, S. Herzog, K. Frese, H. Scheefers, and R. Rott, "Behavioral disease in rats causesd by immunopathological responses to presistent borna virus in the brain," Science, vol. 220, no. 4604, pp. 1401-1403, 1983.

[10] O. Narayan, S. Herzog, K. Frese, H. Scheefers, and R. Rott, "Pathogenesis of borna disease in rats: immune-mediated viral ophthalmoencephalopathy causing blindness and behavioral abnormalities," Journal of Infectious Diseases, vol. 148, no. 2, pp. 305-315, 1983.

[11] N. Hirano, M. Kao, and H. Ludwig, "Persistent, tolerant or subacute infection in Borna disease virus-infected rats," Journal of General Virology, vol. 64, no. 7, pp. 1521-1530, 1983.

[12] W. Dittrich, L. Bode, H. Ludwig, M. Kao, and K. Schneider, "Learning deficiencies in Borna disease virus-infected but clinically healthy rats," Biological Psychiatry, vol. 26, no. 8, pp. 818-828, 1989.

[13] S. A. Rubin, R. W. Waltrip II, J. R. Bautista, and K. M. Carbone, "Borna disease virus in mice: host-specific differences in disease expression," Journal of Virology, vol. 67, no. 1, pp. 548$552,1993$.

[14] L. Stitz, H. Krey, and H. Ludwig, "Borna disease in rhesus monkeys as a model for uveo-cerebral symptoms," Journal of Medical Virology, vol. 6, no. 4, pp. 333-340, 1980.

[15] H. Sprankel, K. Richarz, H. Ludwig, and R. Rott, "Behavior alterations in tree shrews (Tupaia glis, Diard 1820) induced by Borna disease virus," Medical Microbiology and Immunology, vol. 165, no. 1, pp. 1-18, 1978. 
[16] W. I. Lipkin and T. Briese, "Bornaviridae," in Field's Virology, D. M. Knipe and P. M. Howley, Eds., vol. 2, pp. 1829-1851, Lippincott Williams \& Wilkins, Philadelphia, Pa, USA, 5th edition, 2007.

[17] APMIS, "From animals to man-50 years of development. Proceedings of the International Berlin Symposium on Bornavirus Infections," APMIS. Supplementum, no. 124, pp. 3-97, 2008.

[18] M. V. Solbrig and G. F. Koob, "Neuropharmacological sequelae of persistent CNS viral infections: lessons from Borna disease virus," Pharmacology Biochemistry and Behavior, vol. 74, no. 4, pp. 777-787, 2003.

[19] M. V. Solbrig, G. F. Koob, J. H. Fallon, and W. I. Lipkin, "Tardive dyskinetic syndrome in rats infected with Borna disease virus," Neurobiology of Disease, vol. 1, no. 3, pp. 111119, 1994.

[20] G. Gosztonyi and H. Ludwig, "Borna diseaseneuropathology and pathogenesis," Current Topics in Microbiology and Immunology, vol. 190, pp. 39-73, 1995.

[21] M. V. Solbrig, G. F. Koob, and W. I. Lipkin, "Cocaine sensitivity in Borna disease virus-infected rats," Pharmacology Biochemistry and Behavior, vol. 59, no. 4, pp. 1047-1052, 1998.

[22] M. V. Solbrig, G. F. Koob, L. H. Parsons, et al., "Neurotrophic factor expression after CNS viral injury produces enhanced sensitivity to psychostimulants: potential mechanism for addiction vulnerability," The Journal of Neuroscience, vol. 20, article RC104, pp. 1-5, 2000.

[23] M. V. Solbrig, G. F. Koob, J. N. Joyce, and W. I. Lipkin, “A neural substrate of hyperactivity in Borna disease: changes in brain dopamine receptors," Virology, vol. 222, no. 2, pp. 332 338, 1996.

[24] M. V. Solbrig, G. F. Koob, J. H. Fallon, S. Reid, and W. I. Lipkin, "Prefrontal cortex dysfunction in Borna disease virus (BDV)infected rats," Biological Psychiatry, vol. 40, no. 7, pp. 629-636, 1996.

[25] U. Gies, T. Bilzer, L. Stitz, and J. F. Staiger, "Disturbance of the cortical cholinergic innervation in Borna disease prior to encephalitis," Brain Pathology, vol. 8, no. 1, pp. 39-48, 1998.

[26] U. Gies, T. J. Görcs, J. Mulder, et al., "Cortical cholinergic decline parallels the progression of Borna virus encephalitis," NeuroReport, vol. 12, no. 17, pp. 3767-3772, 2001.

[27] J. R. Bautista, G. J. Schwartz, J. C. de la Torre, T. H. Moran, and K. M. Carbone, "Early and persistent abnormalities in rats with neonatally acquired Borna disease virus infection," Brain Research Bulletin, vol. 34, no. 1, pp. 31-40, 1994.

[28] M. Hornig, H. Weissenböck, N. Horscroft, and W. I. Lipkin, "An infection-based model of neurodevelopmental damage," Proceedings of the National Academy of Sciences of the United States of America, vol. 96, no. 21, pp. 12102-12107, 1999.

[29] M. V. Pletnikov, T. H. Moran, and K. M. Carbone, "Borna disease virus infection of the neonatal rat: developmental brain injury model of autism spectrum disorders." Frontiers in Bioscience, vol. 7, pp. D593-D607, 2002.

[30] H. Weissenböck, M. Hornig, W. F. Hickey, and W. I. Lipkin, "Microglial activation and neuronal apoptosis in bornavirus infected neonatal lewis rats," Brain Pathology, vol. 10, no. 2, pp. 260-272, 2000.

[31] M. V. Pletnikov, S. A. Rubin, G. J. Schwartz, K. M. Carbone, and T. H. Moran, "Effects of neonatal rat Borna disease virus (BDV) infection on the postnatal development of the brain monoaminergic systems," Developmental Brain Research, vol. 119, no. 2, pp. 179-185, 2000.

[32] M. V. Pletnikov, S. A. Rubin, M. W. Vogel, T. H. Moran, and K. M. Carbone, "Effects of genetic background on neonatal
Borna disease virus infection-induced neurodevelopmental damage-part II: neurochemical alterations and responses to pharmacological treatments," Brain Research, vol. 944, no. 1-2, pp. 108-123, 2002.

[33] D. M. Dietz, M. W. Vogel, S. A. Rubin, T. H. Moran, K. M. Carbone, and M. V. Pletnikov, "Developmental alterations in serotoninergic neurotransmission in Borna disease virus (BDV)-infected rats: a multidisciplinary analysis," Journal of Neurovirology, vol. 10, no. 5, pp. 267-277, 2004.

[34] L. M. Eisenman, R. Brothers, M. H. Tran, et al., "Neonatal Borna disease virus infection in the rat causes a loss of Purkinje cells in the cerebellum," Journal of Neurovirology, vol. 5, no. 2, pp. 181-189, 1999.

[35] M. V. Pletnikov, S. A. Rubin, T. H. Moran, and K. M. Carbone, "Exploring the cerebellum with a new tool: neonatal Borna disease virus (BDV) infection of the rat's brain," Cerebellum, vol. 2, no. 1, pp. 62-70, 2003.

[36] B. L. Williams and W. I. Lipkin, "Endoplasmic reticulum stress and neurodegeneration in rats neonatally infected with borna disease virus," Journal of Virology, vol. 80, no. 17, pp. 86138626, 2006.

[37] B. L. Williams, K. Yaddanapudi, C. M. Kirk, A. Soman, M. Hornig, and W. I. Lipkin, "Metallothioneins and zinc dysregulation contribute to neurodevelopmental damage in a model of perinatal viral infection," Brain Pathology, vol. 16, no. 1, pp. 1-14, 2006.

[38] B. L. Williams, K. Yaddanapudi, M. Hornig, and W. I. Lipkin, "Spatiotemporal analysis of purkinje cell degeneration relative to parasagittal expression domains in a model of neonatal viral infection," Journal of Virology, vol. 81, no. 6, pp. 2675-2687, 2007.

[39] B. L. Williams, M. Hornig, K. Yaddanapudi, and W. I. Lipkin, "Hippocampal poly(ADP-ribose) polymerase 1 and caspase 3 activation in neonatal bornavirus infection," Journal of Virology, vol. 82, no. 4, pp. 1748-1758, 2008.

[40] M. V. Pletnikov, M. L. Jones, S. A. Rubin, T. H. Moran, and K. M. Carbone, "Rat model of autism spectrum disorders: genetic background effects on borna disease virusinduced developmental brain damage," Annals of the New York Academy of Sciences, vol. 939, pp. 318-319, 2001.

[41] S. Avishai-Eliner, K. L. Brunson, C. A. Sandman, and T. Z. Baram, "Stressed-out, or in (utero)?" Trends in Neurosciences, vol. 25, no. 10, pp. 518-524, 2002.

[42] M. V. Ovanesov, K. Moldovan, K. Smith, M. W. Vogel, and M. V. Pletnikov, "Persistent Borna Disease Virus (BDV) infection activates microglia prior to a detectable loss of granule cells in the hippocampus," Journal of Neuroinflammation, vol. 5, article 16, 2008.

[43] C. Sauder and J. C. de La Torre, "Cytokine expression in the rat central nervous system following perinatal Borna disease virus infection," Journal of Neuroimmunology, vol. 96, no. 1, pp. 29-45, 1999.

[44] C. R. Plata-Salamán, S. E. Ilyin, D. Gayle, A. Romanovitch, and K. M. Carbone, "Persistent Borna disease virus infection of neonatal rats causes brain regional changes of mRNAs for cytokines, cytokine receptor components and neuropeptides," Brain Research Bulletin, vol. 49, no. 6, pp. 441-451, 1999.

[45] C. Sauder, W. Hallensleben, A. Pagenstecher, et al., "Chemokine gene expression in astrocytes of Borna disease virus-infected rats and mice in the absence of inflammation," Journal of Virology, vol. 74, no. 19, pp. 9267-9280, 2000.

[46] D. C. Hooper, S. T. Ohnishi, R. Kean, Y. Numagami, B. Dietzschold, and H. Koprowski, "Local nitric oxide production in viral and autoimmune diseases of the central nervous system," 
Proceedings of the National Academy of Sciences of the United States of America, vol. 92, no. 12, pp. 5312-5316, 1995.

[47] D. C. Hooper, R. B. Kean, G. S. Scott, et al., "The central nervous system inflammatory response to neurotropic virus infection is peroxynitrite dependent," Journal of Immunology, vol. 167, no. 6, pp. 3470-3477, 2001.

[48] D. Gonzalez-Dunia, M. Watanabe, S. Syan, M. Mallory, E. Masliah, and J. C. de La Torre, "Synaptic pathology in Borna disease virus persistent infection," Journal of Virology, vol. 74, no. 8, pp. 3441-3448, 2000.

[49] C. Köster-Patzlaff, S. M. Hosseini, and B. Reuss, "Loss of connexin36 in rat hippocampus and cerebellar cortex in persistent Borna disease virus infection," Journal of Chemical Neuroanatomy, vol. 37, no. 2, pp. 118-127, 2009.

[50] W. Kamitani, Y. Shoya, T. Kobayashi, et al., "Borna disease virus phosphoprotein binds a neurite outgrowth factor, amphoterin/HMG-1," Journal of Virology, vol. 75, no. 18, pp. 8742-8751, 2001.

[51] A. Diamond, "Rate of maturation of the hippocampus and the developmental progression of children's performance on the delayed non-matching to sample and visual paired comparison tasks," Annals of the New York Academy of Sciences, vol. 608, pp. 394-433, 1990.

[52] C. R. Plata-Salamán, S. E. Ilyin, D. Gayle, A. Romanovitch, and K. M. Carbone, "Persistent Borna disease virus infection of neonatal rats causes brain regional changes of mRNAs for cytokines, cytokine receptor components and neuropeptides," Brain Research Bulletin, vol. 49, no. 6, pp. 441-451, 1999.

[53] A. Thorsell, M. Michalkiewicz, Y. Dumont, et al., "Behavioral insensitivity to restraint stress, absent fear suppression of behavior and impaired spatial learning in transgenic rats with hippocampal neuropeptide Y overexpression," Proceedings of the National Academy of Sciences of the United States of America, vol. 97, no. 23, pp. 12852-12857, 2000.

[54] W. Kamitani, E. Ono, S. Yoshino, et al., "Glial expression of Borna disease virus phosphoprotein induces behavioral and neurological abnormalities in transgenic mice," Proceedings of the National Academy of Sciences of the United States of America, vol. 100, no. 15, pp. 8969-8974, 2003.

[55] M. Rauer, J. Götz, D. Schuppli, P. Staeheli, and J. Hausmann, "Transgenic mice expressing the nucleoprotein of Borna disease virus in either neurons or astrocytes: decreased susceptibility to homotypic infection and disease," Journal of Virology, vol. 78, no. 7, pp. 3621-3632, 2004.

[56] J. Hausmann, W. Hallensleben, J. C. de La Torre, et al., “T cell ignorance in mice to Borna disease virus can be overcome by peripheral expression of the viral nucleoprotein," Proceedings of the National Academy of Sciences of the United States of America, vol. 96, no. 17, pp. 9769-9774, 1999.

[57] M. Kao, H. Ludwig, and G. Gosztonyi, "Adaptation of Borna disease virus to the mouse," Journal of General Virology, vol. 65, no. 10, pp. 1845-1849, 1984.

[58] W. Hallensleben, M. Schwemmle, J. Hausmann, et al., "Borna disease virus-induced neurological disorder in mice: infection of neonates results in immunopathology," Journal of Virology, vol. 72, no. 5, pp. 4379-4386, 1998.

[59] C. Sauder, W. Hallensleben, A. Pagenstecher, et al., "Chemokine gene expression in astrocytes of Borna disease virus-infected rats and mice in the absence of inflammation," Journal of Virology, vol. 74, no. 19, pp. 9267-9280, 2000.

[60] C. Sauder, D. P. Wolfer, H.-P. Lipp, P. Staeheli, and J. Hausmann, "Learning deficits in mice with persistent Borna disease virus infection of the CNS associated with elevated chemokine expression," Behavioural Brain Research, vol. 120, no. 2, pp. 189-201, 2001.

[61] C. Sauder, I. Herpfer, C. Hässler, and P. Staeheli, "Susceptibility of Borna disease virus to the antiviral action of gammainterferon: evidence for species-specific differences," Archives of Virology, vol. 149, no. 11, pp. 2171-2186, 2004.

[62] E. Stögmann, A. Zimprich, C. Baumgartner, S. AullWatschinger, V. Höllt, and F. Zimprich, "A functional polymorphism in the prodynorphin gene promotor is associated with temporal lobe epilepsy," Annals of Neurology, vol. 51, no. 2, pp. 260-263, 2002.

[63] M. Simonato and P. Romualdi, "Dynorphin and epilepsy," Progress in Neurobiology, vol. 50, no. 5-6, pp. 557-583, 1996.

[64] M. V. Solbrig, R. Adrian, J. Baratta, J. C. Lauterborn, and G. F. Koob, "Kappa opioid control of seizures produced by a virus in an animal model," Brain, vol. 129, no. 3, pp. 642-654, 2006. 


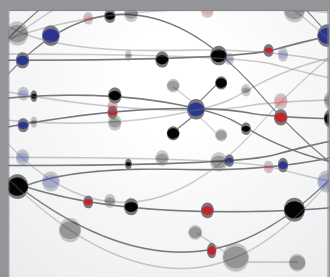

The Scientific World Journal
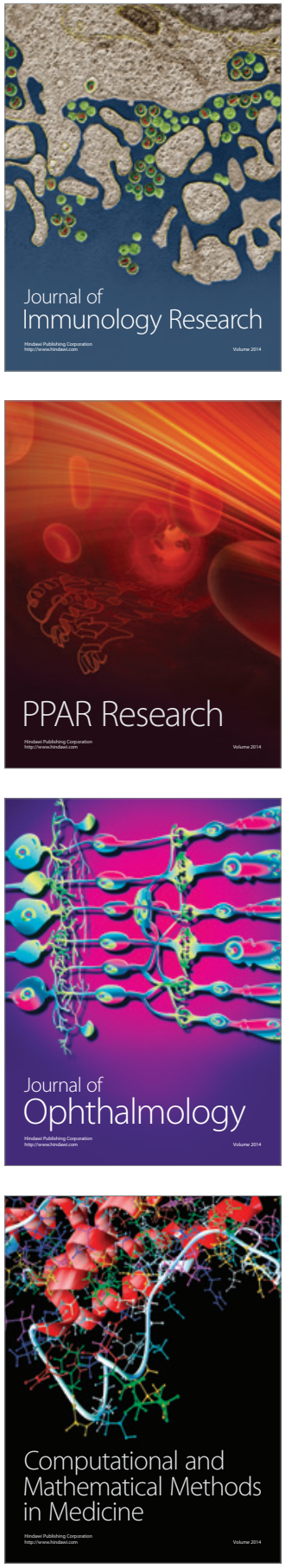

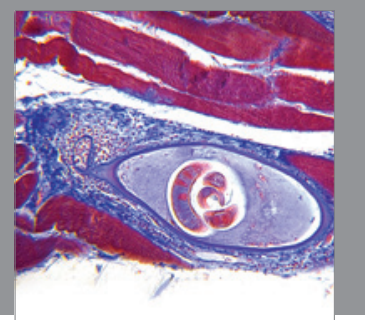

Gastroenterology

Research and Practice
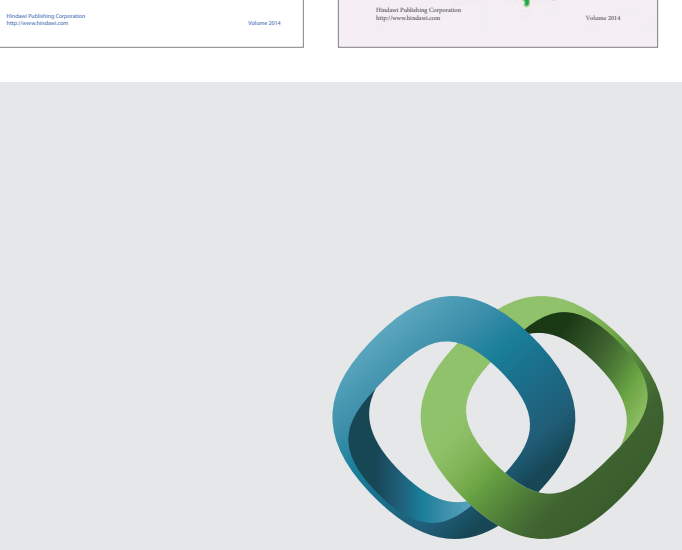

\section{Hindawi}

Submit your manuscripts at

http://www.hindawi.com
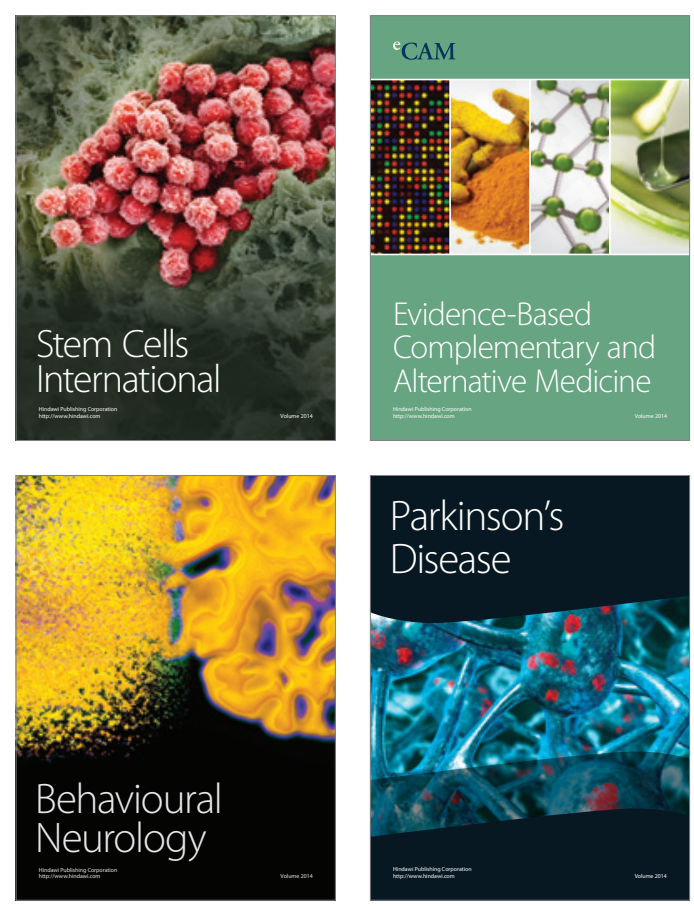

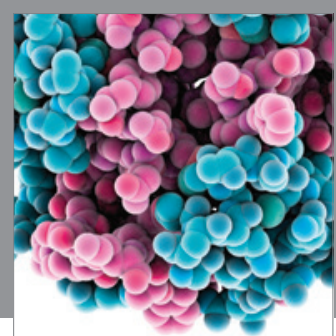

Journal of
Diabetes Research

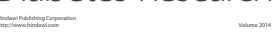

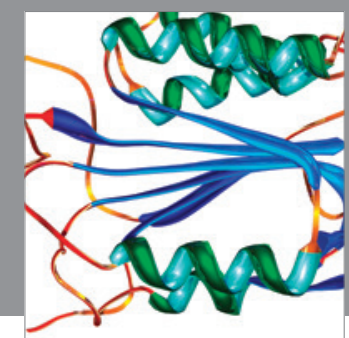

Disease Markers
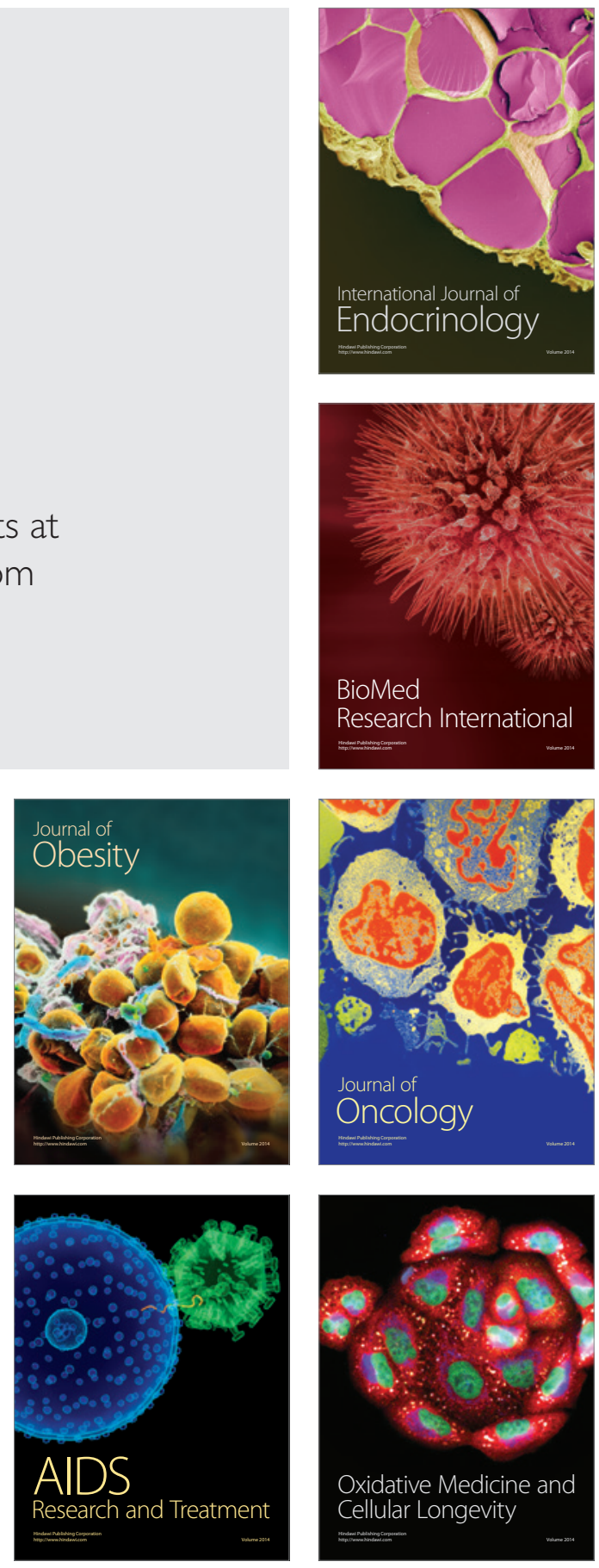